\title{
Geophysical surveys in the southern part of the Central Sakhalin Fault based on new integrated network
}

\author{
Pavel A. Kamenev ${ }^{1 *}$ \\ Dmitry V. Kostylev ${ }^{1,2}$ \\ Natalia V. Boginskaya ${ }^{1}$ \\ Alexander S. Zakupin ${ }^{1}$
}

\author{
${ }^{1}$ Institute of Marine Geology and Geophysics, FEB RAS, \\ Yuzhno-Sakhalinsk, Russia \\ ${ }^{2}$ Sakhalin Branch, Federal Research Center "United Geophysical \\ Service of the Russian Academy of Sciences ", Yuzhno-Sakhalinsk, \\ Russia \\ *E-mail:p.kamenev@imgg.ru
}

\begin{abstract}
Peферат PDF Rus
A surveys system involved seismic stations (broadband and short-period), a hydrophone and a network for recording the level of subsurface radon has been deployed in the vicinity of the active fault of southern Sakhalin. A database on these geophysical fields has been created. The noise level and registration capabilities of seismic equipment have been assessed. The anomaly of variations OA Rn of subsurface radon after a seismic event in the observed region is highlighted. It is shown that the deployed geophysical system can control the Aniva gas field located in the registration zone and the seismological monitoring of gas production is proper. During the period of surveys the approbation of the modern, innovative equipment based on molecular-electronic technology is carried out.
\end{abstract}

\section{Keywords}

seismicity, monitoring, active fault, innovative geophysical equipment, geophysical observations, seismic event

For citation: Kamenev P.A., Kostylev D.V., Boginskaya N.V., Zakupin A.S. Geophysical surveys in the southern part of the Central Sakhalin Fault based on new integrated network. Geosystems of Transition Zones, 2019, vol. 3, no. 4, pp. 390-402. (In Russian) https://doi.org/10.30730/2541-8912.2019.3.4.390-402

Для цитирования: Каменев П.А., Костылев Д.В., Богинская Н.В., Закупин А.С. Геофизические исследования в южной части Центрально-Сахалинского разлома с использованием нового комплекса оборудования. Геосистемы переходных зон. 2019. Т. 3, № 4. С. 390-402. https://doi.org/10.30730/25418912.2019.3.4.390-402

\section{References}

1. Авдюхина С.Ю., Агафонов В.М., Егоров Е.В. и др. Устройство и принцип действия молекулярноэлектронного гидрофона // Прикладные технологии гидроакустики и гидрофизики: Tpуды XIV Всерос. конф. Санкт-Петербург, 23-25 мая 2018 г. СПб., 2018. С. 621-624.

2. Агафонов В.М., Егоров И.В., Шабалина А.С. Принципы работы и технические характеристики малогабаритного молекулярно-электронного сейсмодатчика с отрицательной обратной связью // Сейсмические приборы. 2013. T. 49, № 1. C. 5-18. [Agafonov V.M., Egorov I.V., Shabalina A.S. Operating principles and technical characteristics of portable molecular-electronic seismic sensor with negative feedback. Seismic Instruments, 2014, 50(1): 1-8. https://doi.org/10.3103/s0747923914010022]

3. Алиев А.А. Грязевой вулканизм Южно-Каспийского нефтегазоносного бассейна // Геология $u$ полезные ископаемые Мирового океана. 2006. № 3. С. 35-51.

4. Борисов А.С., Борисов С.А. Оценка параметров гидроакустических сигналов высокочастотной геоакустической эмиссии в районе Центрально-Сахалинского разлома = [Borisov A.S., Borisov S.A. 
Estimation of parameters of hydroacoustic signals of high frequency geoacoustic emission within Central Sakhalin Fault area] // Геосистемы переходных зон = Geosystems of Transition Zones. 2017. № 3. С. 64 70. doi.org/10.30730/2541-8912.2017.1.3.064-070

5. Булгаков Р.Ф., Иващенко А.И., Ким Ч.У., Сергеев К.Ф., Стрельцов М.И., Кожурин А.И., Бесстрашнов В.М., Стром А.Л., Сузуки Я., Цуцуми Х., Ватанабе М., Уеки Т., Шимамото Т., Окумура К., Гото Х., Кария Я. Активные разломы северо-восточного Сахалина // Геотектоника. 2002. № 3. C. 66-86.

6. Воейкова О.А., Несмеянов С.А., Серебрякова Л.И. Неотектоника и активные разломы Сахалина. М.: Наука, 2007. 187 с.

7. Дрознин Д.В., Дрознина С.Я. Интерактивная программа обработки сейсмических сигналов DIMAS // Сейсмические приборы. 2010. T. 46, № 3. C. 22-34. [Droznin D.V., Droznina S.Y. Interactive DIMAS program for processing seismic signals. Seismic Instruments, 2011, 47(3): 215-224. https://doi.org/10.3103/s07479239110300541

8. Ершов В.В. Флюидодинамические процессы в зоне Центрально-Сахалинского разлома (по результатам наблюдений на Южно-Сахалинском грязевом вулкане) // Geodynamics \& Tectonophysics. 2012. T. 3, № 4. С. 345-360. https://doi.org/10.5800/GT-2012-3-4-0078

9. Закупин А.С., Богинская Н.В. Современная сейсмичность в районе Центрально-Сахалинского разлома (юг о. Сахалин): ложная тревога или отодвинутый прогноз? = Zakupin A.S., Boginskaya N.V. Modern seismicity in the area of the Central Sakhalin fault (south of Sakhalin Island): false alarm or postponed prediction? // Геосистемы переходных зон = Geosystems of Transition Zones. 2019. Т. 3, № 1 . C. 27-34. doi:10.30730/2541-8912.2019.3.1.027-034

10. Злобин Т.К., Бобков А.О. Современная сейсмичность и разломная тектоника юга Сахалина. ЮжноСахалинск: Изд-во СахГУ, 2003. 124 с.

11. Каменев П.А., Заболотин А.Е., Дегтярев В.А., Жердева О.А. Разработка геомеханической модели активного разлома южного Сахалина = Kamenev P.A., Zabolotin A.E., Degtyarev V.A., Zherdeva O.A. Geomechanical model of South Sakhalin active fault // Геосистемы переходных зон $=$ Geosystems of Transition Zones. 2019. T. 3, № 3. C. 287-295. doi.org/10.30730/2541-8912.2019.3.3.287-295

12. Козлова И.А., Юрков А.К. Методические вопросы измерения содержания радона-222 в почвенном воздухе при мониторинговых наблюдениях // Уральский геофизический вестник. 2005. № 7. С. 3134.

13. Костылев Д.В., Богомолов Л.М., Каменев П.А., Закупин А.С., Богинская Н.В. Комплексный сейсмический мониторинг в районе Анивского газового месторождения // Нефтегазовый комплекс: проблемы и решения: материалы Первой начиональной науч.-практ. конф. Южно-Сахалинск: СахГУ, 2018. С. 11-12.

14. Кучай В.К. Современная орогенная структура южной части о. Сахалин // Тихоокеанская геология. 1987. № 1. С. 50-57.

15. Макаров Е.О., Фирстов П.П., Костылев Д.В. и др. Первые результаты мониторинга подпочвенного радона сетью пунктов, работающей в тестовом режиме, на юге острова Сахалин // Вестник КРАУНЦ. Физико-математические науки. 2018. № 5 (25). С. 99-114. doi: 10.18454/2079-6641-201825-5-99-114

16. Мельников О.А. Дислокации и сейсмичность южной части зоны Тымь-Поронайского взбросонадвига // Тектоника, геодинамика, магматизм, металлогения и сейсмичность Тихоокеанского сегмента Земли. Южно-Сахалинск: ИМГиГ ДВО РАН, 2002. С. 50-87.

17. Мишаткин В.Н., Захарченко Н.З., Чебров В.Н. Технические средства сейсмической подсистемы службы предупреждения о цунами // Сейсмические приборы. 2011. Т. 47, № 1. С. 26-51. [Mishatkin V.N., Zakharchenko N.Z., Chebrov V.N. Hardware for the seismic subsystem of the tsunami warning service. Seismic Instruments, 48(1): 16-33. https://doi.org/10.3103/s0747923912010100]

18. Никитенко О.А., Ершов В.В., Перстнева Ю.А., Бондаренко Д.Д., Балогланов Э.Э., Аббасов О.Р. Вещественный состав продуктов деятельности грязевых вулканов Сахалина и Азербайджана: сравнительный анализ = Nikitenko O.A., Ershov V.V., Perstneva Ju.A., Bondarenko D.D., Baloglanov E.E., Abbasov O.R. Substance composition produced by mud volcanoes of Sakhalin Island and Azerbaijan: the first comparison // Геосистемы переходных зон = Geosystems of Transition Zones. 2018. Т. 2, № 4. C. 346-358. doi:10.30730/2541-8912.2018.2.4.346-358

19. Прытков А.С., Василенко Н.Ф. Деформации земной поверхности острова Сахалин по данным GPSнаблюдений // Геодинамика и тектонофизика. 2018. Т. 9, № 2. С. 503-514. doi:10.5800/GT-2018-9-20358

20. Рождественский В.С., Сапрыгин С.М. Активные разломы и сейсмичность на Южном Сахалине // Тихоокеанская геология. 1999. № 6. С. 59-70.

21. Рудаков В. П. Эманационный мониторинг геосред и процессов. М.: Научный мир, 2009. 175 с.

22. Сапрыгин С.М. Тектоника плит и сейсмичность в Дальневосточном регионе. Южно-Сахалинск: Сахалин. кн. изд-во, 2005. 83 с.

23. Тютрин И.И., Дуничев В.М. Тектоника и нефтегазоносность северо-западной части Тихоокеанского пояса. М.: Недра, 1985. 174 с. 
24. Тютрин И.И., Дуничев В.М., Табояков А.Я. Основные геологические результаты поисков нефти и газа на Южном Сахалине // Советская геология. 1981. № 3. С. 37-41.

25. Уткин В.И., Юрков А.К. Радон как индикатор геодинамических процессов // Геология и геофизика. 2010. Т. 51, № 2. С. 277-286.

26. Borisov A.S., Borisov S.A., Levin B.W., Sasorova E.V. Hydroacoustic observations of weak earthquakes in shallow waters of the Southern Kuril Islands // Geodynamics \& Tectonophysics. 2012. Vol. 3(2). P. 103113. doi:10.5800/GT-2012-3-2-0065.

27. Chaudhuri H., Ghose D., Bhandari R.K., Sen P., Sinha B. A geochemical approach to earthquake reconnaissance at the Baratang mud volcano, Andaman and Nicobar Islands // J. of Asian Earth Sciences. 2012. Vol. 46. P. 52-60. http://dx.doi.org/10.1016/j.jseaes.2011.10.007.

28. Kostylev D.V., Bogomolov L.M., Boginskaya N.V. About seismic observations on Sakhalin with the use of molecular-electronic seismic sensors of new type // IOP Conf. Series: Earth and Environmental Science. 2019. Vol. 324, 012009. doi:10.1088/1755-1315/324/1/012009

29. Levin B.W., Sasorova E.V., Zakupin A.S., Kamenev P.A. Local occurrence of the relationship between variations in the Earth's rotation rate and the dynamics of seismicity: Case study of Sakhalin // Doklady Earth Science. 2018. Vol. 483, N 2. P. 1575-1578. https://doi.org/10.1134/s1028334x18120188

30. Makarov E., Firstov P., Kostylev D. et al. Test mode of operation network of monitoring subsoil radon in the south of Sakhalin // E3S Web Conf. (IX Intern. Conf. "Solar-Terrestrial Relations and Physics of Earthquake Precursors”). 2018. Vol. 62, 03007. DOI: https://doi.org/10.1051/e3sconf/20186203007

31. Peterson J. Observations and modeling of seismic background noise. U.S. Geol. Survey Open-File Report. 1993. N 93-322. 94 p. https://doi.org/10.3133/ofr93322

32. Polets A.Yu. The stress state of the Sakhalin Island and adjacent territories // IOP Conf. Series: Earth and Environmental Science. 2019. Vol. 324, 012010. https://doi.org/10.1088/1755-1315/324/1/012010

33. Shakirov R., Obzhirov A., Suess E., Salyuk A., Biebow N. Mud volcanoes and gas vents in the Okhotsk Sea area // GeoMarine Letters. 2004. Vol. 24(3). P. 140-149. http://dx.doi.org/10.1007/s003670040177y

34. Yang T.F., Fu C.C., Walia V. et al. Seismogeochemical variations in SW Taiwan: multiparameter automatic gas monitoring results // Pure and Applied Geophysics. 2006. Vol. 163(4). P. 693-709. https://doi.org/10.1007/s00024-006-0040-3 